\title{
Short communication \\ Effects of a starch binding agent on in vitro rumen degradability of maize and sorghum starch
}

\author{
M.N.T. Shipandeni ${ }^{1,2}$, C.W. Cruywagen ${ }^{1}$ \& E. Raffrenato ${ }^{1,3 \#}$ \\ ${ }^{1}$ Department of Animal Sciences, Stellenbosch University, Private Bag X1, Matieland, 7602, South Africa \\ ${ }^{2}$ Department of Animal Sciences, University of Namibia, Private Bag 13301, Windhoek, Namibia
}

${ }^{3}$ R\&D RUM\&N Sas, Reggio Emilia, Italy

(Submited 14 March 2020; Accepted 10 October 2020; Published 7 December 2020)

\begin{abstract}
Copyright resides with the authors in terms of the Creative Commons Attribution 4.0 South African Licence.
See: http://creativecommons.org/licenses/by/4.0/za

Condition of use: The user may copy, distribute, transmit and adapt the work, but must recognise the authors and the South African Journal of Animal Science.
\end{abstract}

\begin{abstract}
The objective of the study was to quantify the potential of a starch binding agent (BioProtect ${ }^{\mathrm{TM}}$ ) to reduce in vitro rumen starch degradation of maize and sorghum particles that varied in size. Maize and sorghum grain samples were ground through 2-mm sieves with a Wiley mill and subsequently sieved to obtain these sizes: less than 250, 250 - 500, 500 - 1180, and 1180 - $2000 \mu \mathrm{m}$ (i.e., very fine to coarse). All fractions were analysed separately for starch content. Samples were treated 24 hours before fermentation by spraying BioProtect onto the substrate. Both treated and untreated samples were fermented in vitro for 0,6 , 12 and 24 hours to quantify starch degradability. Rates of degradability $\left(k_{d}\right)$ were calculated with a first-order decay model. BioProtect was effective in decreasing starch degradability and rates of degradability for both grains $(P<0.0001)$. The product was more effective with smaller particle size, by reducing starch degradability $17 \%$ for the smallest particles as opposed to $7 \%$ for the largest particles. A time interaction was observed $(P<0.0001)$, which showed that the highest impact of BioProtect occurred after 12 hours of fermentation for both grains. The starch binding agent resulted in an effective decrease of in vitro starch degradation, but results were affected by particle size and fermentation time. Starch digestion could possibly be shifted to the small intestine with BioProtect.
\end{abstract}

Keywords: BioProtect, rates of degradation, starch digestibility

"Corresponding author: emiliano@sun.ac.za

Although the optimal site of starch digestion is debatable (Reynolds, 2006; Owens et al., 2016), strategies that partially shift starch digestion and absorption post ruminally continue to evolve with the aim of increasing the efficiency of nutrient utilization, hence improving the performance of dairy cows. This is because excessive ruminal fermentability, may cause a severe drop in ruminal $\mathrm{pH}$, resulting in ruminal acidosis, decreased fibre digestibility and lower efficiency of microbial protein production (Firkins et al., 2001). It also results in reduced feed intake (Allen, 2000), altered rumen biohydrogenation (Bauman \& Griinari, 2001), and ultimately decreased milk production. Starch that flows to the small intestine can be digested enzymatically, resulting in the production of glucose, fermented in the hindgut to volatile fatty acids (VFA) or excreted. Shifting the site of starch digestion to the small intestine could overcome problems encountered with excessive ruminal fermentability. Moreover, other potential benefits include higher energy efficiency (30\% to $42 \%$ higher) (Owens et al., 1986), leading to higher metabolizable energy utilization, increased supply of glucogenic substrates, and increased milk protein production. This releases amino acids from being used for gluconeogenesis in the liver (Huhtanen \& Sveinbjörnsson, 2006).

Traditionally, the processing of maize and sorghum focused on increasing rumen digestibility to meet the energy demands of high-producing dairy cows to optimize milk income over feed costs and efficiency. However, during certain physiological stages, decreasing rumen digestion and shifting the site of digestion may be useful for these reasons. There have been several studies on the potential of shifting the site of starch digestion to the small intestine by using various starch sources or by processing or chemical treatments (e.g. sodium hydroxide $(\mathrm{NaOH})$ and formaldehyde $(\mathrm{HCHO})$ ). However, strategies aimed at 
shifting the site of starch digestion from the rumen to the small intestine will be successful only if it is digested extensively there (Bird et al., 1999).

Recently, there has been interest in a product named BioProtect (Realistic Agri, Ironbridge, UK), a starch binding agent. The active ingredient in BioProtect is a stable non-volatile organic salt that complexes with the hydroxyl groups of starch at neutral or slightly acidic conditions ( $\mathrm{pH} 6$ to 7), as observed in the rumen. These complexes decompose under more acidic (pH 2 to 3 ) conditions, as in the abomasum and duodenum, making the starch available for enzymatic digestion (Dunshea et al., 2012). BioProtect has been claimed to decrease the rate of rumen fermentation of highly digestible starch and to increase the rate of starch utilization post ruminally (Dunshea et al., 2012, 2013; Gonzalez et al., 2014). However, Gonzalez et al. (2014) recommended further in vitro and in vivo studies to confirm these claims. More recently, Van Zyl (2017) reported a positive effect of BioProtect on in vitro starch disappearance of coarsely ground (4-mm screen) low vitreous maize, but none on finely ground (1-mm) low vitreous maize. In the in vivo trial, Van Zyl (2017) reported that BioProtect decreased total tract starch digestibility of maize, contrary to Gonzalez et al. (2014), who recorded that BioProtect did not reduce whole tract starch digestibility of wheat in sheep. Although these authors used different starch sources, the effectiveness of BioProtect is still not clear. Moreover, these studies focused on processing grains simply by grinding them through various sieves and therefore reducing particle size, but also obtaining a variable distribution of particles, which could affect starch digestibility (Firkins et al., 2001). Within grain type, various fragment sizes (sieve fractions) possess different surface area characteristics, which affect the magnitude of starch digestion (Al-Rabadi et al., 2012). The potential of BioProtect on maize and sorghum of different particle sizes needs to be investigated. Therefore, the objective of this study was to quantify the potential of a starch-binding agent (BioProtect) to reduce in vitro rumen starch degradation of maize and sorghum that varied in particle size.

Maize and sorghum grains were ground through a 2-mm sieve using a Wiley mill and subsequently sieved to obtain these particle sizes: $<250,250-500,500-1180$, and $1180-2000 \mu \mathrm{m}$ (i.e., from very fine to coarse). All fractions were analysed separately for starch (Hall, 2009). Samples were treated 24 hours before fermentation by spraying them with BioProtect according to the product guidelines (8 L/tonne of cereal grain). Treated and untreated maize and sorghum samples were fermented in vitro (Goering \& Van Soest, 1970) for $0,6,12$, and 24 hours to quantify starch degradability. Rumen fluid was collected from two ruminally cannulated Holstein dairy cows before morning feeding and mixed in pre-warmed insulated thermos flasks at Welgevallen Experimental Farm of Stellenbosch University. Cows were fed a total mixed ration consisting of roughage $(40 \%)$ and a concentrate mixture $(60 \%)$. Rumen fluid was filtered through two layers of cheesecloth, glass wool, and a double layer of $200 \mu \mathrm{m}$ filter paper before injecting $10 \mathrm{ml}$ into a $125-\mathrm{mL}$ Erlenmeyer flask with $0.25 \mathrm{~g}$ of substrate and $40 \mathrm{ml}$ of Van Soest buffer for incubation at $39.5^{\circ} \mathrm{C}$ under $\mathrm{CO}_{2}$ (Goering \& Van Soest.,1970). Blank flasks without substrate were used to correct for possible starch from the rumen fluid. The residual starch was determined using the entire incubated content of samples in flasks (that is, residue plus medium) and therefore soluble starch was included in the resulting starch content. Three separate runs were conducted for each cereal in duplicates of each sample for each incubation time.

Rates of digestion $\left(\mathrm{k}_{\mathrm{d}}\right)$ were computed using a first-order decay model according to this equation:

$$
S_{(t)}=S_{(0)} e^{-k d(t-L)}+u S ;
$$

where: $S_{(t)}$ is residual starch at time $t$,

$\mathrm{S}_{(0)}$ is starch at time 0 of the soluble and insoluble starch,

$k_{d}$ is the fractional rate of starch digestion,

$L$ is the lag, and

uS is the estimated indigestible starch.

Simultaneous estimates of the parameters were obtained using PROC NLIN (version 9.3, SAS Institute, Inc., Cary, North Carolina, USA) and the Marquardt algorithm. Resulting parameters and starch degradability were analysed according to a randomized complete block design with a factorial arrangement of particle size, cereal, BioProtect treatment, time (for starch degradability only) and interactions by the GLIMMIX procedure. The main effects were grain, particle size, product, time (for starch degradability only) and their interactions. Fermentation run $(n=3)$ was considered a random effect. Differences between means were declared significant at $P \leq 0.05$ using the LSMEANS and the Tukey adjustment.

Starch degradability and rate of starch degradation $\left(\mathrm{K}_{\mathrm{d}}\right)$ increased linearly with decreased particle size $(P<0.0001)$ for both types of grain. Starch degradability and $\mathrm{K}_{\mathrm{d}}$, when time points were pooled, increased from $41.75 \%$ and $58.20 \%$ and from $10.80 \%$ to $26.40 \% / \mathrm{h}$, respectively, for maize. The correspondent values for sorghum increased similarly from $30.45 \%$ to $53.78 \%$ for starch degradability and from $11.20 \%$ to 24.40 $\% / h$ for $\mathrm{K}_{\mathrm{d}}($ Table 1$)$. In agreement with previous studies, starch degradation was inversely related to particle 
size (Ferraretto et al., 2013). Decreasing the particle size increased the surface area available for bacteria attachment or enzymatic digestion (Huntington, 1997; Ferraretto et al., 2013; Gallo et al., 2016), resulting in an increased rate and extent of starch degradation (Nocek \& Tamminga, 1991). In addition to the surface area effects, starch in coarse or large particles is harboured in granules in the endosperm, still protected by the pericarp, which is the foremost barrier, limiting microbial accessibility to starch granules (Huntington, 1997), hence reducing starch degradability.

Overall, BioProtect was effective $(P<0.0001)$ in decreasing starch degrading for maize and sorghum grains (Table 2). When time and size were pooled, the extent of starch degradation decreased from $55.65 \%$ to $45.75 \%$ in maize, and from $48.44 \%$ to $37.47 \%$ in sorghum. When particle size was pooled, treatment decreased $\mathrm{K}_{\mathrm{d}}$ from $25.21 \%$ to $14.40 \% / \mathrm{h}$ and from $18.80 \%$ to $13.50 \% / \mathrm{h}$ for maize and sorghum, respectively. Interestingly, Van Zyl (2017) reported that BioProtect was not effective in decreasing in vitro starch fermentation when maize was milled through a 1-mm screen, irrespective of vitreousness, but was effective on low vitreous maize milled with a 4-mm screen. In the same study, BioProtect decreased the $K_{d}$ of 4-mm ground low vitreous maize by 4 percentage units.

Table 1 Effects of particle size on the rate and extent of degradability of maize and sorghum starch

\begin{tabular}{llccccccc}
\hline & \multicolumn{5}{c}{ Particle size } & \\
\cline { 3 - 5 } & & Very fine & Fine & Medium & Coarse & SE & $P$-value \\
\hline \multirow{2}{*}{ Maize } & Starch degradability, \% & $58.20^{\mathrm{a}}$ & $53.55^{\mathrm{b}}$ & $49.29^{\mathrm{c}}$ & $41.75^{\mathrm{d}}$ & 0.045 & $<0.0001$ \\
& \multirow{3}{*}{ Sorghum } & $26.40^{\mathrm{a}}$ & $23.00^{\mathrm{b}}$ & $19.00^{\mathrm{c}}$ & $10.80^{\mathrm{d}}$ & 0.021 & $<0.0001$ \\
& $\mathrm{~K}_{\mathrm{d}, \% / \mathrm{h}}$ & Starch degradability, \% & $53.78^{\mathrm{a}}$ & $47.08^{\mathrm{b}}$ & $40.52^{\mathrm{c}}$ & $30.45^{\mathrm{d}}$ & 0.046 & $<0.0001$ \\
& $\mathrm{~K}_{\mathrm{d}, \% / \mathrm{h}}$ & $24.40^{\mathrm{a}}$ & $14.10^{\mathrm{b}}$ & $14.80^{\mathrm{b}}$ & $11.20^{\mathrm{c}}$ & 0.041 & $<0.0001$
\end{tabular}

${ }^{\mathrm{a}-\mathrm{d}}$ Within a row, means with a common superscript were not different at $P=0.05 ; \mathrm{K}_{\mathrm{d}}$ : rate of degradation

The variability in response in these studies could be explained by differences in techniques, methodology, grains, degree of processing of grains, and the amount and process of BioProtect incorporation. BioProtect decreased the rate of ruminal starch fermentation of wheat in a dose-dependent manner $(0,4,8$, and $16 \mathrm{ml} / \mathrm{kg})$, with response maximized at $8 \mathrm{ml} / \mathrm{kg}$, hence the product guideline of application rate of $8 \mathrm{~L}$ per tonne (Dunshea et al., 2013).

Table 2 Effects of a starch binding agent on the rate and degradability of maize and sorghum starch

\begin{tabular}{llcccc}
\hline & & Untreated & BioProtect -treated & SEM & $P$-value \\
\hline \multirow{2}{*}{ Maize } & Starch degradability, \% & $55.65^{\mathrm{a}}$ & $45.75^{\mathrm{b}}$ & 0.044 & $<0.0001$ \\
& $\mathrm{~K}_{\mathrm{d}}, \% / \mathrm{h}$ & $25.20^{\mathrm{a}}$ & $14.40^{\mathrm{b}}$ & 0.021 & $<0.0001$ \\
\multirow{3}{*}{ Sorghum } & Starch degradability, \% & $48.44^{\mathrm{a}}$ & $37.47^{\mathrm{b}}$ & 0.046 & $<0.0001$ \\
& $\mathrm{~K}_{\mathrm{d}}, \% / \mathrm{h}$ & $18.80^{\mathrm{a}}$ & $13.50^{\mathrm{b}}$ & 0.041 & $<0.0001$
\end{tabular}

${ }^{a-b}$ Within a row, means with a common superscript were not different at $P=0.05 ; \mathrm{K}_{\mathrm{d}}$ : rate of degradation

The effects of BioProtect on maize and sorghum starch degradation of varying particle sizes are presented in Figure 1. When the results were compared, the product was more effective with smaller particle size, reducing starch degradability by 17 percentage units for the smallest particles as opposed to 7 percentage units for the largest particles. This result implied that the binding agent was more efficient with finer particles where starch was highly degradable, and with a disrupted protein matrix and disorganized starch granules. It could also be due to the accessibility of starch and its interaction with the product (BioProtect). Starch granules in particles larger than $500 \mu \mathrm{m}$ will predominantly be within intact cell walls, whereas particles smaller than $250 \mu \mathrm{m}$ would be expected to have many broken cells with exposed intracellular content (Al-Rabadi et al., 2009). Besides, BioProtect had more access to starch in finer particles, 
possibly because of the surface area available for reaction between BioProtect and starch, making starch more exposed for BioProtect contact. The product was therefore able to bind more efficiently to starch in finer particles inhibiting its fermentation.
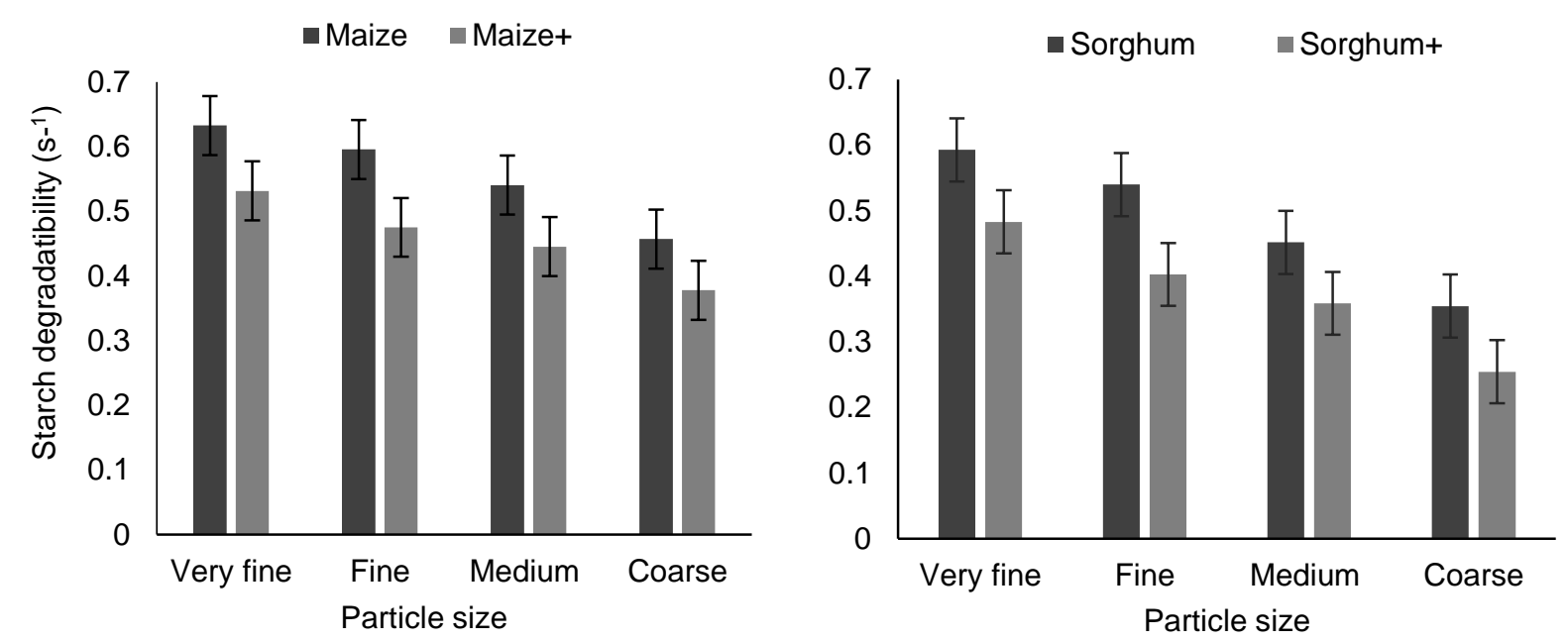

Figure 1 Effect of a starch binding agent on maize and sorghum starch degradation of varying particle sizes

Overall, untreated grains showed higher degradability throughout the incubation period with most of the starch having disappeared by 24 hours of incubation (Figure 2).

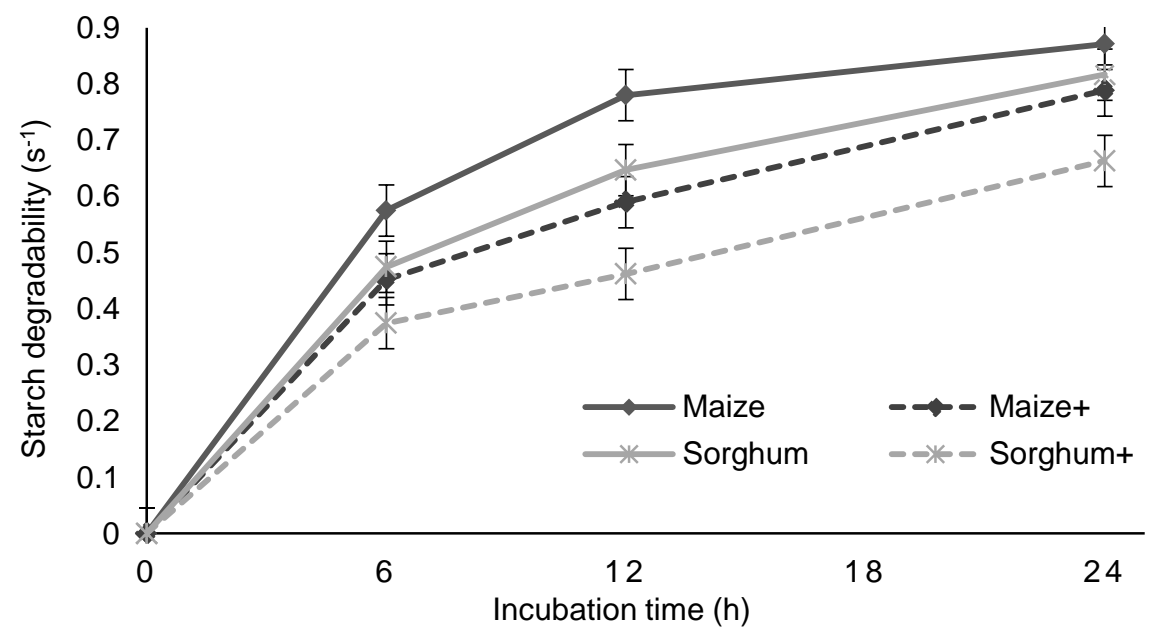

Figure 2 Effect of a starch binding agent on maize and sorghum starch degradation at 0, 6, 12 and 24 hours of incubation

A time interaction was observed $(P<0.0001)$, showing that the highest impact of BioProtect occurred after 12 hours of fermentation for both grains, with 19 and 18 percentage unit decreases in starch degradability of BioProtect-treated maize and sorghum, respectively. However, in ruminants, the extent to which starch is fermented in the rumen is dependent on the retention time of the feed in the rumen, and that is more important when considering the proportion of ruminal starch digestion. A reasonable mean retention time of concentrate in the rumen of lactating dairy cows is seven hours (Allen \& Piantoni, 2014; Gallo et al., 2016). After seven hours of rumen retention, starch that is not fermented in the rumen flows to the small intestine, where enzymatic starch digestion occurs. This unfermented starch is not considered for the ruminal starch pool. In this study, the starch degradability for untreated grains reached $57 \%$ and $47 \%$ after 6 hours of incubation in maize and sorghum, which was reduced to $45 \%$ and $37 \%$ in BioProtect-treated maize and sorghum, respectively. At six hours, BioProtect decreased starch degradability by $12 \%$ and $10 \%$-units in maize and sorghum, respectively. Thus, more starch could possibly be shifted to the small intestines with 
BioProtect treatment. In conclusion, BioProtect, a starch binding agent, reduced in vitro rumen starch degradation of maize and sorghum grains, giving an opportunity to increase the amount of starch shifted to the small intestine, but results would be affected by particle size and fermentation time.

\section{Acknowledgment}

The authors would like to thank the National Research Foundation (NRF) of South Africa for funding these experiments through the project titled 'Starch as modulator of productive and reproductive function in dairy cows' (Grant No: CSUR 13092748692).

\section{Authors' Contributions}

All authors participated in the planning of the experiments, data analysis and reviewed the manuscript. MNT was responsible for the in vitro laboratory analysis and wrote the manuscript.

\section{Conflict of Interest Declaration}

Authors declare that there is no conflict of interest for this work.

\section{References}

Al-Rabadi, G.J.S., Gilbert, R.G. \& Gidley M.J., 2009. Effect of particle size on kinetics of starch digestion in milled barley and sorghum grains by porcine alpha-amylase. J. Cereal Sci. 50,198-204.

Al-Rabadi, G.J., Torley, P.J., Williams, B.A., Bryden, W.L. \& Gidley, M.J., 2012. Particle size heterogeneity in milled barley and sorghum grains: Effects on physico-chemical properties and starch digestibility. J. Cereal Sci. 56:396403. DOI: 10.1016/j.jcs.2012.04.009

Allen, M.S., 2000. Effects of diet on short-term regulation of feed intake by lactating dairy cattle. J. Dairy Sci. 83,15981624. DOI: $10.3168 /$ jds.S0022-0302(00)75030-2

Allen, M.S. \& Piantoni, P., 2014. Carbohydrate nutrition: Managing energy intake and partitioning through lactation. Vet. Clin. North Am. - Food Anim. Pract. 30, 577-597. DOI: 10.1016/j.cvfa.2014.07.004

Bauman, D. \& Griinari, J., 2001. Regulation and nutritional manipulation of milk fat: Low-fat milk syndrome. Livest. Prod. Sci. 70, 15-29. DOI: 10.1016/S0301-6226(01)00195-6

Bird, S.H., Rowe, J.B., Choct, M., Stachiw, S., Tyler, P. \& Thompson, R.D., 1999. In vitro fermentation of grain and ezymatic digestion of cereal strach. Recent Adv. Anim. Nutr. Aust. 12, 53-61.

Dunshea, F., Russo, V., Sawyer, I. \& Leury, B.J., 2012. A starch-binding agent decreases the in vitro rate of fermentation of wheat. J. Anim. Sci. 90, 158.

Dunshea, F.R., Russo, V.M., Sawyer, I. \& Leury, B.J., 2013. A starch binding agent decreases the rate of fermentation of wheat in a dose-dependent manner. Book of Abstracts of 64th Annual Meeting of European Association Federation of Animal Science: EAAP Scientific Committee. Wageningen Academic, The Netherlands.

Ferraretto, L.F., Crump, P.M. \& Shaver, R.D., 2013. Effect of cereal grain type and corn grain harvesting and processing methods on intake, digestion, and milk production by dairy cows through a meta-analysis. J. Dairy Sci. 96, 53350. DOI: $10.3168 /$ jds.2012-5932

Firkins, J.L., Eastridge, M.L., St-Pierre, N.R. \& Noftsger, S.M., 2001. Effects of grain variability and processing on starch utilization by lactating dairy cattle. J. Anim. Sci. 79, E218-E238.

Gallo, A., Giuberti, G. \& Masoero, F., 2016. Gas production and starch degradability of corn and barley meals differing in mean particle size. J. Dairy Sci. 99, 4347-4359. DOI: 10.3168/jds.2015-10779

Goering, H. \& Van Soest, P., 1970. Forage fiber analyses. Agric. Handb. No. 379.US Dep. Agric. Washington, DC. Pp.12-20.

Gonzalez, P., Price, M., Digiaconomo, K., Henry, M.L., Leury, B., Russo, V., Cakebread, P. \& Dunshea, F., 2014. Rumen protection of wheat with a starch binding agent does not reduce whole tract digestibility in sheep. proc. Aust. Soc. Anim. Prod 30, 107.

Hall, M.B., 2009. Analysis of starch, including maltooligosacchardies, in animal feeds: A comparison of methods and a recommended method for AOAC collaborative study. J. AOAC Int. 92, 42-49.

Huhtanen, P. \& Sveinbjörnsson, J., 2006. Evaluation of methods for estimating starch digestibility and digestion kinetics in ruminants. Anim. Feed Sci. Technol. 130, 95-113. DOI: 10.1016/j.anifeedsci.2006.01.021

Huntington, G.B., 1997. Starch utilization by ruminants: From basics to the bunk. J. Anim. Sci. 75, 852. DOI: $10.2527 / 1997.753852 x$

Nocek, J.E. \& Tamminga, S., 1991. Site of digestion of starch in the gastrointestinal tract of dairy cows and its effect on milk yield and composition. J. Dairy Sci. 74, 3598-3629. DOI: 10.3168/jds.S0022-0302(91)78552-4

Owens, F.N., Zinn, R.A. \& Kim, Y.K., 1986. Limits to starch digestion in the ruminant small intestine. J. Anim. Sci. 63, 1634. DOI: $10.2527 /$ jas $1986.6351634 x$

Owens, C.E., Zinn R.A., Hassen, A. \& Owens, F.N., 2016. Mathematical linkage of total-tract digestion of starch and neutral detergent fiber to their fecal concentrations and the effect of site of starch digestion on extent of digestion and energetic efficiency of cattle. Prof. Anim. Sci. 32, 531-549. DOI: 10.15232/pas.2016-01510

Reynolds, C.K., 2006. Production and metabolic effects of site of starch digestion in dairy cattle. Anim. Feed Sci. Technol. 130:78-94. DOI: 10.1016/j.anifeedsci.2006.01.019

Van Zyl, J.H.C., 2017. The effect of maize vitreousness and a starch binder on in vitro fermentation parameters and starch digestibility in dairy cows. Thesis (PhD), Stellenbosch University, South Africa. 